\section{THE THEORY OF NATURAL SELECTION FROM A MATHEMATICAL POINT OF VIEW}

THE fascinating hypothesis of Darwinism has, within the last few years, so completely taken hold of the scientific mind, both in this country and in Germany, that almost the whole of our rising men of science may be classed as belonging to this school of thought. Probably since the time of Newton no man has had so great an influence over the development of scientific thought as Mr. Darwin; and no one can over-estimate the debt which Science owes to his patient researches and his clear insight into some of the hidden ways of Nature. The advocates of Darwinism have, however, almost invariably failed to recognise that the theory consists of two essentially distinct portions, one of which may be admitted while the other is denied. The first portion is that witl which the name of Darwin is popularly associated, although its origination is by no means due to him, namely, the probable ancestry of all forms of living organism from a single or a few original germs; the other portion, and that which we especially owe to his genius, is the theory that the infinite modifications of existing forms owe their origin to a process of Natural Selection from spontaneous variations. These two perfectly distinct hypotheses have generally been so confounded together that those who have attacked or defencied the one have also attacked or defended the other. My object in the present paper is to show that, while the former hypothesis may be considered as established, as nearly as it is possible to establish a theory which requires thousands or millions of years for its complete development, the arguments in support of the second hypothesis are far less satisfactory.

The principle that new forms of organic life have been produced by modifications of older nearly-allied forms is by no means a new one; its inherent reasonableness and probability commended it to Lamarck and the author of the "Vestiges of Creation" long before it was elaborated in a more scientific form by Mr. Darwin and Mr. Wallace. It has been opposed, of course, by theologians; but, were it not that the theological mind is inherently averse to the reception of new ideas, it would have been seen that the supposition that the Creative Power works by continuous modification and adaptation of contrivance to end, by a constant exercise of $\mathrm{His}$ prerogative, is a far higher tribute to $H$ is exalted attributes, than the popular dogma that all living things were created as we now see them by one single gigantic effort, after which the power collapsed, and has never since been exercised. Why should organic life be the one thing in the world not subject to change? The conts de grace may be considered to have been given to the anciently received theory by the investigations so ably carried out by Mr. Darwin and Dr. Hooker on the characteristics of Insular Floras. The fact that no island which has been separated from the mainland during recent sreological epochs has genera, and scarcely even species, of animals or plants peculiar to itself, while islands which have remained isolated during lengthened geological periods have faline and floræ almost entirely peculiar to themselves, is inexplicable on any other hypothesis than that of the gradual differentiation of species by long-continued separation. No more striking instance of this law has been given than that afforled by the East Indian Islands, as shown in Mr. Wallace's "Malay Archipelago." Two great types of animals and plants are found in different regions of the archipelaso, the IndoMalavan and the Australian; and these two types are separated, not by any diversity of climate and soil-not even by any of the wide but shallow channels which indicate recent separation, such as that between Borneo and Sumatra-but by the narrow but very deep channel separating Bali from Lombok, which indicates a lengthened geological separation of two continents at this point.

The hypothesis that the prime agent in all these infinite modifications is the principle of Natural Selection from spontaneous variations, has been recently further illustrated by Mr. Wallace's volume of Essays, "Contributions to the Theory of Natural Selection;" and it is mainly from the illustrations furnished in this work that I propose to derive my arguments as to its inadequacy. In the first place I wish to call attention to the fact which the Duke of Argyll has already acutely pointed out in his "Reign of Law," that the thicory does not even attempt to explain the most inexplicable phenomenon in the development of these organic changt: namely, the first commencement of a

* Paper read before Section D of the British Association, at Liverpool, September $2 \mathrm{cth}, 1870$. tendency to variation. 'The title of Mr. Darwin's famous work, the text-book of the theory, seems to me, indeed, altogether a misnomer: "The Origin of Spccies by means of Natural Selection." Mr. Darwin admits the existence of what he terms a "spontaneous" tendency to variation among the offspring from a common ancestor; this "spontaneous". tendency is the only natural law which can correctly be termed that of the origin of species; all that Mr. Darwin and his disciples attempt to explain is the survival and propagation of certain among the diverse forms thus resulting in preference to others. Throughout the whole of Mr. Wallace's volume he appears to have no consciousness that his theory does not go to the root of the matter. When once the tendency to change has set in, there can be no doubt that "Natural Selection," "The Survival of the Fittest," whatever you like to term the principle, is one among many causes which tend to the perpetuation of certain forms. Wheln, however, Mr. Darwin asserts, "I am convinced that Natural Selection has been the main, but not exclusive, means of modification," I I am by no means prepared to go with him to that extent. Some of Mr. Darwin's disciples go even further, and seem to consider it, in fact, as almost the only means.

There is no phenomenon in Natural History which is more thoroughly relied on by the advocates of Natural Selection as furnishing a decisive argument in favour of their theory, than the one which forms the subject of the longest of the essays in $\mathrm{Mr}$. Wallace's volume, that of Mimicry or Mimetism. I propose, therefore, to occupy the greater part of this paper with an inquiry how far the facts which have been adduced support the conclusions first brought prominently forward by $\mathrm{Mr}$. Bates in his "Naturalist on the Amazons," and more fully elaborated and illustrated by Mr. Wallace. There can be no doubt about the frequent occurrence of "protective resemblances" in the animal kingdom. Certain classes of animals enjoy, from various catses, exceptional immunity from the attacks of their natural enemies. In order to share in these immunities, it is found that other animals, belonging to an entirely different class or order, whilst retaining all the structural characters of their own class, so closely resemble in external features of colour and form particular species of the favoured races as to be readily mistaken for them. How do the advocates of the theory of Natural Selection attempt to account for this superficial resemblance? By the continuous preservation, through countless generations, of those particular individuals which spontaneously approach most nearly to the ultimate forms.

Now, there are two principles admitted or insisted on by every advocate of Darwinism, which it is necessary to bear very clearly in mind in the following argument. The first is, that, in a state of nature those differences which nltimately become specific or generic are brought about by exceedingly slow gradations. And it is obvious that it must be so. For if by chance any strongly abnormal form is produced, even should it survive to generate offspring, which is in itself doubtful, it must necessarily cross with other less abnormal individuals, and its descendants would thus have a tendency to revert towards the parental form. On this point Mr. Darwin himself says : "It may be doubted whether sudden and great deviations of structure, such as we occasionally see in our domestic productions, are ever perma. nently propagated in a state of nature." + And again, "Natural Selection always acts with extreme slowness." $¥$ The other point which $I$ wish to be borne in mind is, that no change can possibly take place by the process of Natural Selection which is not directly of advantage to the individual. On this point again all the supporters of the hypothesis are agreed. $\mathrm{Mr}$. Darwin distinctly affirms that "only those variations which are in some way profitable, will be preserved or naturally selected ;" $\S$ and Mr. Wallace even more emphatically spealss of " the principle which Mr. Darwin so earnestly impresses upon us, and which is, indeed, a necessary deduction from the theory of Natural Selection, namely, that none of the definite facts of organic nature, no special organ, no characteristic form or marking, no peculiarities of instinct or of habit, no relations between species or between groups of species-can exist, but which must now be or once have been usefil to the individuals or the races which possess them." $\|$

We have, therefore, established at the outset these two data: that the passage from the ordinary to the mimetic form is effected by a number of exceedingly small steps, and * "Prigis of Species," 4th ed., p. 6. + Ibid, p. 47. I Ibid, p. I2I.

II "Coritributions to the Theory of Natural Selection," p. 47 
that every one of these changes must present some advantage to the species which undergoes it. Now let us apply these two principles to the recognised facts of Mimetism; and for this purpose we may take a single instance, one of the most remarkable and best authenticated, recorded by Mr. Bates in his "Naturalist on the Amazons," and more fully in his paper on the "Lepidoptera of the Amazon Valley," in the "Transactions of the Iimean Society." There is in South America a tribe of butterflies of very gaudy colour, the Heliconida, which appear to enjoy exceptional immunity from the attacks of birds, from the exudation, when attacked, of a nauseous fluid, and are consequently extremely abundant. Another South American genus of Lepidoptera, the Leptalis, belongs structurally to an entirely different class, the Pierida, and the majority of its species differ correspondingly from the Heliconida, in their size, shape, colour, and manner of flying, being nearly pure white, and of the same family as our common cabbage butterfly. There is, however, one particular species of Leptalis, which departs widely in externai facies from all its allies, and so closely resembles a species of Ithomia belonging to the Heliconide, as apparently not only to deceive the most experienced entomologists, but even to take in its natural enemies also, and, although perfectly hamless, to share the immunity of the butterfly it simulates. Mr. Bates and Mr. Wallace have both attempted to show, with great ingenuity and plausibility, that this entire clange from the normal form to that resembling the Ithomia has taken place through the agency of natural selection acting through a long series of generations. I believe, however, on careful examination, the line of argument will be found to break down, and that at its very outset, on the ground that the early stages of the transformation will be perfectly useless for the protection of the species.

Applying the rigid test of mathematical calculation to the problem, I think it may safely be assumed that it would require, at the very lowest calculation, one thousand steps to enable the normal Leptalis to pass into its protective form. Mr. Bates indeed assumes that the change may have taken place much more rapidly, but this appears a very unsafe and unsupported deviation from the sounder principle laid town by Darwin and Wallace. It is indeed obvious that any marked variety resulting suddenly must inevitably revert, as already observed, more and more towards the parent type by crossing, unless, indeed, we are to suppose that a pair, male and female, are simultaneously produced with a deviation in exactly the same direction, and that their offspring keeps itself apart, interbreeding only with itself as a separate colony, -an assumption contrary to all experience. At all events, we may safely say that within the historic period no such change has been effected within a vastly larger number of generations, where human agency has not come into play. The next step in my argumerit is, that the smallest change in the direction of the Ithomia, which we can conceive on any hypothesis to be beneficial to the Leplalis, is at the very lowest one-fiftieth of the change required to produce perfect resemblance. I believe myself that a very much larger fraction, say one-fourth or one-third, would be practically useless; as I am told by practical entomologists that birds will distinguish with accuracy caterpillars suited for their food from other species scarcely distinguishable to our eyes, which are not so suitable. For the sake of argument, however, I will suppose that a change to the extent of one-fiftieth is beneficial to that small extent after which natural selection may begin to come into play. Mr. Wallace, indeed, argues that an infinitesimal and inappreciable distinction may make the difference of a slightly longer span of life being allowed to the butterfly, to lay its eggs in safety ; but this is a deductive piece of reasoning derived from the theory, because necessary to it, and not inductive observation from nature and I altogether decline to be carried further, for the sake of the theory, than the limit I have indicated. Suppose a parallel instance : that our common brown owl has a penchant for mice, while moles are abhorrent to its palate ; is it conceivable that, supposing a mouse was born approaching a mole by the onehundredth part in external appearance, say with feet a fraction of a line broader, or eyes slightly deeper set, the shortest-sighted of owls would for a moment mistake Mus for Talpa? Or, a still more parallel instance: sippose a blue-bottle fly were born blessed with a slightly narrower waist, or a faint band of yellow on its body, will any one maintain that it stands the least chance of escape from destruction by those birds which do not feed on wasps? And no one who has examined Mr.
Bates's or Mr. Trimen's beautiful drawings, or, still better, the insects themselves, will say that I have exaggerrated the extent of the passage from the normal to the imitative Leptalis.

If, therefore, this reasoning is sound, one thousand steps being necessary to effect this change in external appearance, and onefiftieth of the whole change, or twenty steps, being the smallest amount that is really profitable to the animal, it follows that the first twenty steps of the transformation are not due to natural selection, but must have taken place by an accumulation of chances. Let us investigate the value of this chance. Suppose there are twenty different ways in which a Leptalis may vary, one only of these being in the direction nitimately required, the chance of any individual producing a descendant which will take its place in the succeeding generation varying in the required direction, is $\frac{I}{20}$; the chance of this operation being repeated in the same direction in the second generation is $\frac{\mathrm{I}}{2 \mathrm{O}^{2}}$ or $\frac{\mathrm{I}}{400}$; the chance of this occurring for ten successive generations (instead of twenty, as I have assumed above) is $\frac{\mathrm{I}}{2 \mathrm{O}^{10}}$, or about one in ten billions. Now another factor comes into the calculation, and that is the number of individuals among which this chance is distributed. Mr. Bates and Mr. Wallace agree in stating that both in South America and in the Malay Archipelago the imitative species are always confined to a limited area, and are always very scarce compared with the imitated species. We will assume that the number of individuals of the imitative Leptalis existing at any one time is one million; the chance of there being among these million a single individual approaching the Ithorita to the extent of one-hundredth is $\overline{10600000000000}$, or the chance against it is ten million to one.

It will be seen that in the above calculation I have endeavoured to throw every advantage into the scale of the natural selectionist. I believe myself, and I think most naturalists will agree with me, that vastly more than a thousand generations, each characterised by a small change, must be conceded; and that, on the other hand, a change to the extent of even greatly more than onefiftieth would be absolntely useless. This idea receives great confirmation from observing the most wonderful identity of the marking in the nimicked and mimicker. If a rough imitation is so useful, it must be a mere freak of Nature to produce sis absolute an identity, and we are landed in the dilemma that the last stages are comparatively useless. If, again, I had carried on the calculation to $\frac{\mathrm{I}}{2 \mathrm{O}^{20}}$ instead of $\frac{\mathrm{I}}{2 \mathrm{O}^{10}}$, it would have been difficult to have stated the result in figures; and if, on the other hand, it is objected that a million is too low an estimate of the number of individuals existing at one time, and a hundred million or a thousand million is substituted (an altogether in. conceivable estimate for a rare conspicuous butterfy limited to a small area*), the result will not be materially affected. For, supposing the chance is reduced from one in ten million to one in ten thousand-and it is said that the world has existed quite long enough to give a fair chance of this having occurred onceit is not a solitary instance that we have. Mr. Bates states that, in a comparatively small area, several distinct instances of such perfect mimicry occur; Mr. Wallace has a store in the Malay Archipelago; Mr. Trimen records several of wonderful beauty and exactness in South Africa; and the more attention is turned to the subject, the more numerous do instances of unimicry become.

I have left out of account altogether those still more remarkable instances, which are even more difficult to explain on the theory of natural selection (as the number of steps must be infinitely greater), in which animals not only imitate others belonging to entirely different natural orders, as Diptera mimicking Hymenoptera, and caterpillars snakes, but where they resemble inanimate objects. The weird and uncanny resemblance of the Phasmata and Mantides to dry leaves and sticks has long been known: not only is the veining of the leaves accurately reproduced, but the attacks of parasitic fungi are simulated; and Mr. Wallace records instances of larvæ bearing the most minute resemblance to the droppings of birds, and spiders to the axillary buds of plants. Through what countless generations must these transformations have been effected! and by what mathematical formula could we express the chance against their occurrence, if

* The latter number would give 150 individuals per acre over an area roo miles square, or 50 per acre for an area as large as Ireland. 
natural selection only had been at work in their production? The difficulties in the way of the natural selection explanation are also materially increased when we find, as is often the case, that it is one sex only (the female) which undergoes these mimetic changes, and that the changes have to take place simultaneously in the direction of colour, size, form, and habit.

It may now fairly be asked, if the principle of natural selection is abandoned as the main cause of these wonderful modifications, what other theory can be sulstituted in its place? I do not know that the objector to a theory is always bound to provide tnother theory as a substitute. Mr. Darwin, in his "Variation of Animals and Plants under Domestication," quotes with wellCeserved approval Whewell's aphorism, that "Hypotheses may often be of service to science, when they involve a certain portion of incompleteness, and even of error." Mr. Darwin's and Mr. Wallace's hypothesis of natural selection has been of signal service to science; but if this hypothesis has been too rashly handled and too widely applied, it may be equally serviceable to point out its incompleteness or its error, as the first step to a still more scientific explanation. In the following remarks, I merely wish to call the attention of naturalists to one or two points which I think have almost been lost sight of in the discussion.

I have already adverted to the inaccuracy of the title of Mr. Darwin's great work, "The Orygin of Species by means of Nitural Selection." The opponents of Darwinism, everi so acute a reasoner as the Duke of Argyll, appear to see no alternative between the theory that species have arisen through the agency of external causes, and the theory that species have remained immutable since their creation. I can accept no such alternative. Indeed we may say that external influences cannot be the primary cause of the transmutation of species. The utmost claimed by the theory of natural selection is, that it selects the fittest from already existing so-called "spontaneous" varieties. Every page of Mr. Darwin's work teems with reference to this pre-existing feridency to variation, with respect to which he says: "Oui igtiorance of the laws of variation is profound." Mr. Bates, when speaking on the subject of mimicry, makes the following very remarkable admission :- " "It would seem as though our Leptalis naturally produced simple varieties of a nature to resemble Tthointic." * By a careful study of the context, I can only conrlircle that Mr. Bates means the same thing by his "natural" Farieties as Mr. Darwin does by his "spontaneous" variations, namely, an innate tendency to vary not caused by natural selection, but on which tendency natural selection operates, and without which it would be perfectly inoperative. The use of the terin "spontaneous" is open to objection from a philosophical point of view. It either means that the phenomera in question are subject to no law, or that they are the result of some law with which we are unacquainted. The former hypothesis ivill probably be rejected by every scientific naturalist, and must be utterly abhorrent to the believer in a "Reign of Law." This tenclency to variation in the offspring meets us on every side in our investigation of nature. Every gardener knows how uncertain is the produce of seeds compared with the produce of buds or offshoots from the same plant. The ordinary mode of obtaining new varieties of strawberries or other fruits is from seeds. An endless variety of the commonest florist's flowers is produced by sowirig seeds from the same capsule. Of the laws of this variation we are, as Mr. Darwin says, "profoundly ignorant ;" but it does not follow that a patient interrogation of nature pursued in the true Darwinian spirit, may not reveal to us something of these laws. Of one thing we are certain, that natural selection here plays no part. If then we must admit that the first beginning of change takes place without the operation of this principle, why should we claim for it the main, almost the exchusive agency, in the changes which follow? Some other principle, at present unknown to us, originates these variations; what right have we to say that this principle, whatever it may be, then ceases to act, instead of being the main agent in all the other subsequent changes?

But are we limited to negative evidence in tracing the transintitations of species mainly to some unknown internal law? A single sentence in Mr. Wallace's Chapter on Mimicry seems to me pregnant with results for the future inquirer. He incidentally remarks how frequently it is the case that, when mimicry has orice set in by the action of natural selection, new habits and instincts come into play to assist in the mimicry. It does not, however, appear to occur to Mr. Wallace to trace any connection between the instinct and the mimicry. The connection will be found, I believe, to be very close. Passing by for the moment any definition of instinct, let us trace its range in the organiserl world. From the whole vegetable kingdom it is conspicuous by its absence. In the lowest classes of the animal kingdom, the Protozoa and Colenterata, it is found, if at all, in a very low form; and though there is a popular superstition that oysters may be crossed in love, yet we cannot attribute to the Mollusca as a class any strong development of the instinctive faculty. When, however, we come to the Articulata, and especially to the Insecta and closely allied Arachnida, we meet at once with developments of instinct rivalling, if not exceeding in perfectness, those found in the highest forms of animal life. In the lower orders of Vertebrata again, the Pisces and Reptilia, we apparently come to a retrogression in the instinctive faculty, which is once more strongly developed in the Aves and Mammalia. Now let us compare this with what is known of Mimicry. From the vegetable kingdom it is absent. There are, it is true, resemblances, and resemblances of the most wonderful and perfect kind, in the marking and venation of the leaves of plant belonging to en tircly different natural orders, equal in extraordinary closeness to those of which I have spoken in the animal kingdom; but these are in no sense mimetic or protective. Mere protective resemblances of colour I consider of far less importance than of form or habit; since colour may unquestionably be affected directly by the external circumstances of light, \&c., and varies "spontaneously" in both the animal and vegetable kingdom to a far greater extent than does form. In the luwest forms of animal life we have no well-authenticated instances of nimetism, the most striking among the Moilusca with which I am acquainted is one pointed out to me by Mr. G. S. Brady in the beautiful Lima hians.* But when we come to insects, we find protective resemblances of the most extraordinary kind, in marking, in form, in habit, presented to us on every side. Among fishes and reptiles the principle appears to be again comparatively in abeyance, and to be once more strongly developed in birds. The parallelism is indeed almost complete. In short, the power of mimetism, as far as is known at present, runs almost pari passic with the development of the nervous system.

But what is instinct? Modern raturalists are pretty well agreed in abandoning the old distinction in kind between reason and instinct, and in considering the nest-building instinct of birds and the cell-constructing instinct of bees, as but a lower form of the same faculty which we call reason in ourselves. It is ad. mitted that this instinct teaches the bee which flowers to rifle for its honey, and even to modify its habits in accordance with the circumstances in which it is placed; but, according to the prevalent theory, it has no power to modify its proboncis so as to enable it to obtain the honey from the flower, or to modify its wings to suit to its new habit. In short its own body is almost the only thing over which the animal has no power. To me such a restriction appears to be unphilosophical. I cannot but believe in the existence of an unconscions Oryanising Intelligence, an idea which Mr. J. J. Murphy has ably and logically advocated in his "Habit and Intelligence." And it this inherent innate power of change is admitted, it at once harmonises the tendency to variation which exists in all created beings, with the perpetuation of those forms best adapted to resist the struggle of life, and lends to natural selection the assistance of a fellowworker far more powerful and of more universal operation.

A powerful argument in favour of this view may be drawn from Mr. Wallace's volume. Every reader of that book must have been struck with the remarkable manner in which he com. pletely abandons and casts aside his own theory when he comes to treat of man. Natural selection is amply sufficient to account for all the other transmutations in the animal kingdom; only give time enough, and it is competent to develop the elephant out of the Amaba-the one step in the animal creation which is beyond its power is that from the ape to man; all the infinite forms of the brute creation have resulted from this principle, to produce the different races of mankind sume other power is needed. In a singularly able review of this work in the Archives des Sciences physiques et $N_{\text {cituteiles, }} \mathrm{M}$. Claparede, of lieneva, points out with great acumen the singular inconsistency of this reasoning; and shows how great a want of faith in his own principle it betrays on the part of its author. Mr. Wallace's line of argument is very interesting. We may take only a single instance. Man is the only terrestrial mammal with a bare hair. less back. All savage nations feel the want of a covering to their back; in cold countries to protect them from the cold, in 
hot countries to protict them from the heat of the sun. It is impossible to conceive, therefore, that this absence of covering was ever directly !eneficial to the race or the individual; and hence it cannot have been produced by the operation of natural selection; but mist have been in sume way connected with thove reasoning poincts which lead to the construction of clothing and dwellings on which his civilisation so largely clepends. Mr. Wal. lace, however, appears to forget that he had previously stated his conclusion that "those great modifications of structure and of external form which resulted in the development of man out of some lower type of animal, must have occurred before his intellect had raised him above the conclition of the brutes." This principle, therefore, whatever it may he, other than natural selection, which produced man's bare back, must have been in operation before the intellect of man was develuped. This strange inconsistency of Mr. Wallace's appears to result from the fact that he is unable to shut his eyes to the inevitable conclusion that the development of man from the ape, and the production of the different races of mankind, have not resulted from the operation of natural selection, pure and simple, but that this principle has been powerfully assisted by man's reasoning faculties. This reasoning seems to me perfectly sound and inevitable, admitting, for the sake of argument, Mr. Wallace's hypothesis, that man is descended from the apes; but, if we consistently believe in the action of general laws which govern the whole of animated nature, we must carry the argument back a step further. Reason is but a higher development of instinct. If man's reason has assisted him so to modity his body as to adapt himself to the circumstances with which he is surrounded, we are unable to bring forward any valid argument why the instinct of animals should not also assist them to modify their bodies, by slow and graclual degrees, so as to adapt them to the circumstances with which they are surrounded.

In the essay alluded to above, M. Claparede, himself one of the few genuine Darwinians among French writers, points out the dangerous and unscientific manner in which the theory of natural selection is made, in the hands of its too zeslous advocates, to explain phenomena which are probably due to other causes. The discovery of this law marked an era in the history of natural science, and gave a wonderful imuulse to original research. The danger now is that the law will be pressed into services which have no claim upon it; and that, in the hands of injudicious partisans, it will become a hindrance rather than an aid to science, by closing the door against furcher investiyation in:o other laws which lie behind it. To ciaim for Natural Selection the main agency in the creation of the count ess forms of organic life with which we are surrounded, is straining it beyond its strength. An era of equal importance will be marked by the discovery of the law which regulates the tendency to variation which must necessarily underlie natural selection.

The argument of "clesign" was undoubtedly pushed by preDarwinian writers to too great an extent. The most recent phase of Darwinianism, however, is a complete denial of the existence of design in Nature. It is the carrying into Natural Science of the Hobbesian principle of Self-love. Every individual and every species exists for its own advantage only, and has no raison d"être except its own wellare. To my mind the bear ties and wonders of Nature seem, on the other hand, to teach a different lesson, that,

$$
\text { All are but parts of one stupendous whole, }
$$

that there are laws, albeit almost unknown to us-not laws merely of external circumstance, but laws of internal growth and struc ture, - which actively modify each individual organism, not only for its own advantage in the struggle for life, but for the higher end of subordinating every individual existence to the good of the whole.

\section{Alfred W. BenNetT}

\section{THE PROFESSORSHIP OF NATURAL HIS TOKY, QUEEN'S COLLEGE, BELFAST}

I $\mathrm{N}$ a late number we announced that Professor Wyville Thomson, of the Queen's College; B:lfist, had been appointed by the Crown to the Professorship of Natural History in the University of Edinburgh. This will

\footnotetext{
" "Contrillutions to the Theory of Natural Selection," y. 3rg.
}

necessitate the resignation by Professor Thomson of his ch $+\mathrm{ir}_{\text {in }}$ in the Queen's College, Belfast, a resignation which we may presume $w 11$ bs made before the commencement of the next term, and a resignation in which some of nur readers and many of our men of science will take an interest, foi the piaces of honow nr emolument open to the sturlent of Natural science in this count y are so very lew, that there is naturally much excitement when one of the few is to befilled up. Already we hear of a whole hust of young and meritorious workers setting their faces towards the city that boasts to be the Athens of the North of Ireland. The mere mention of the names of Dr. Cunningham, who in the Straits of Magellan earned his Nacural Science spurs so well, of Mr. E. Ray Lankester, whose numerous papers show an intimate acquaintance with zoology, of Dr. Macalister, whose comparative anatomy memoirs are so well-known, or of Dr. Traquair, whose papers on fossil fish and on the skull of recent Pleuronectida. are of high merit, not to name others, will show that the post of Professor of Natural History in the Queen's College, B ilfast, will be contested for by a lirtle army of well-educated and accomplished gentlemen, the selection of any one of whom would reflect credit on the College.

But a rumour reaches us that there may be no election to the Professorship after all-that the spirit of economy is to annihilate the spirit of competition; that, in order that the Government of this great country may save certain paltry trifling possibilities of pension, it is their intention to tran:late to Belfast one of the four Professors of Natural Science in the Queen's Colleges of Cork and Galway. It is necessaty to explain $h-i w$ this can be done. Each of the Queen's Colleges had originally a Professor of Geolngy and Mineralo:y, and a rofessor of Zoology and lisotany. Their income was that of a junior assistant in the British Museum, and for common decency's sake, it was found necessary to raise it ; this was done on the condition that each of the Pro:essors undertook to lecture on the subjects at the time lectured on by his colleague, on the death or resignation of that colleague, without further increase of pay. So when Prof. Dickie, who was Professor of Botany and Zoology in the Queen's College, Belfast, resigned, on his removal to Aberdeen, Prof. Thomson had to lecture in zoology and botany, in addition to his own subjects of geology and mineralogy. Thus it happens that should the Government confer the vacant Belfa.t chair on one of the four existing Professors of Natural Science in the other two Queen's Colleges, inis post in the college which he leaves will be filled up by his colleague, and the Crown will have to deal in the matter of pension, \&c., with but four persons instead of with five, as they will have if they appoint a candidate who is not one of these four Professors to the vacant post. Nor can the Crown confer this Professorm ship on one of the present Professors, and then fill up the place thus left vacant by a new appointment, because, although the yearly salary of the colleavue of the Professor thus elected will not be increased thereby, yet his fees, to a slight extent, will ; and so, to break the bargain made, would be to the detriment of the individual - a thing, we believe, no Government would do. But why, we ask, should they, for a paltry saving, do detriment to the cause cf Science in this country-collited when she is neededkept at more than arm's length when it is im?gined she may be done without? Science is but badly cared for in our country, and we here allude to the above facts for the purpose of urging those to whose care this appointment falls, to forget, for the once, all considerations except those for the good of the College, and to quicken the already expanding li e of the Queen's University in Ireland by the infusion of fresh bood into this one 0 its Colleges.

It is in the interest of Science that we write, not in the interest of candida'es, one of whose nanies we would not mention above another. 